\title{
Rescue technique using a diathermic dilator for an unremovable stent in malignant perihilar biliary obstruction
}

Endoscopic biliary stenting is a useful and safe technique for malignant biliary obstructions. A plastic stent is frequently used because of its low cost and ease of deployment. However, it is occasionally difficult to remove a plastic stent because of severe stricture. We describe a rescue technique for immovable plastic stents, using a diathermic dilator in a case of perihilar biliary obstruction.

A 63-year-old woman with jaundice due to hilar biliary obstruction was referred to our hospital. A diagnosis of gallbladder cancer was made from findings of a thickened gallbladder wall and massive ascites revealed by computed tomography ( $>$ Fig. 1 ) and magnetic resonance cholangiopancreatography ( $\triangleright$ Fig. 2). For biliary decompression and pathological confirmation, endoscopic retrograde cholangiography (ERC) was performed, and a 7-Fr plastic stent was placed ( $\triangleright$ Fig. 3, $\triangleright$ Video 1).

The patient underwent a second ERC 4 days later because of elevated biliary enzymes. The plastic stent could not be removed using forceps and snares, and the torn-off stent was left in place ( $\triangleright$ Fig.4). Although needle-knife sphincterotomy was performed to expose the residual plastic stent, the stent could not be grasped. A 0.025 -inch guidewire could be advanced alongside the plastic stent, but a sphincterotome (CleverCut 3V; Olympus, Tokyo, Japan) could not. Successful dilation of the perihilar biliary stricture was achieved by advancing a 6-Fr wire-guided diathermic dilator (Cysto-Gastro-Set; Endo-Flex $\mathrm{GmbH}$, Voerde, Germany) (\ Fig.5). However, the remaining plastic stent also migrated. Thus, a 10-mm lumen partially covered, self-expandable, metallic stent (WallFlex biliary stent; Boston Scientific Japan, Tokyo, Japan) was deployed alongside the plastic stent ( $\triangleright$ Fig.6).

In cases of malignant biliary stricture, removal of a plastic stent is time-consuming and might cause complications. The
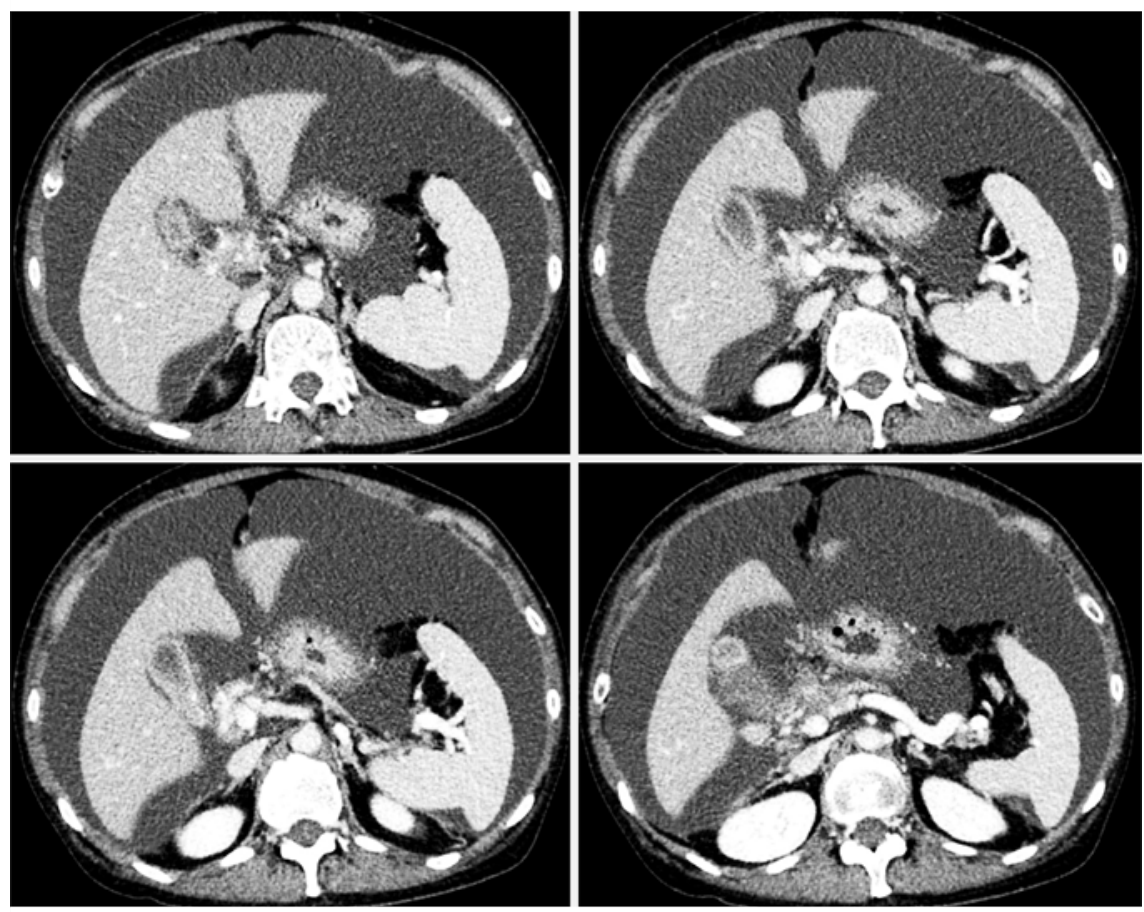

- Fig. 1 Contrast-enhanced computed tomography showed a thickened gallbladder wall and massive ascites.

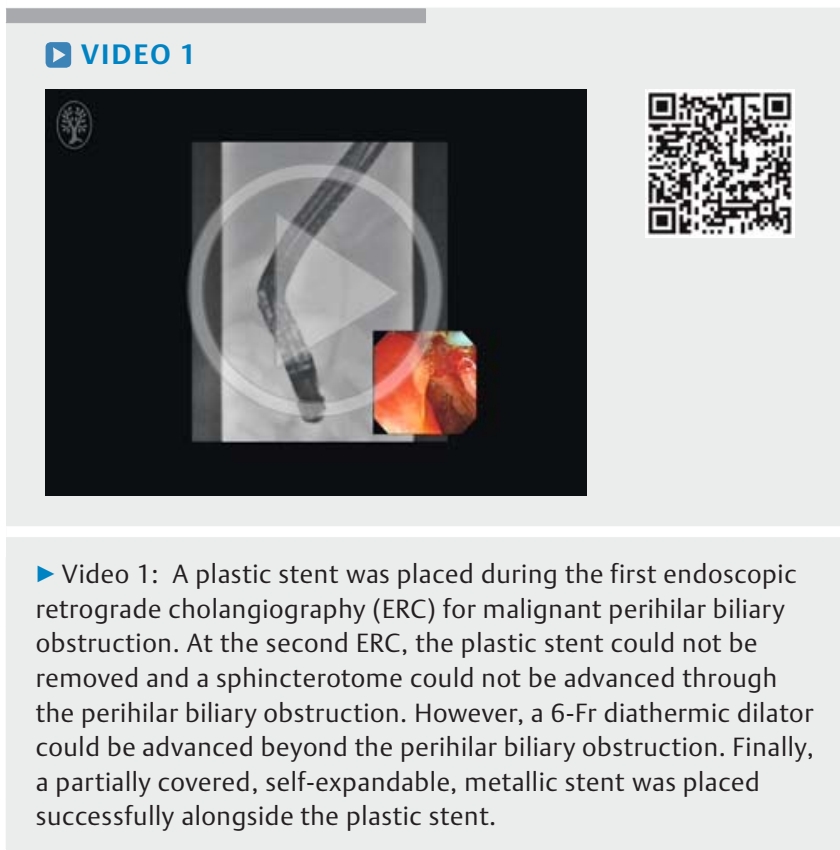



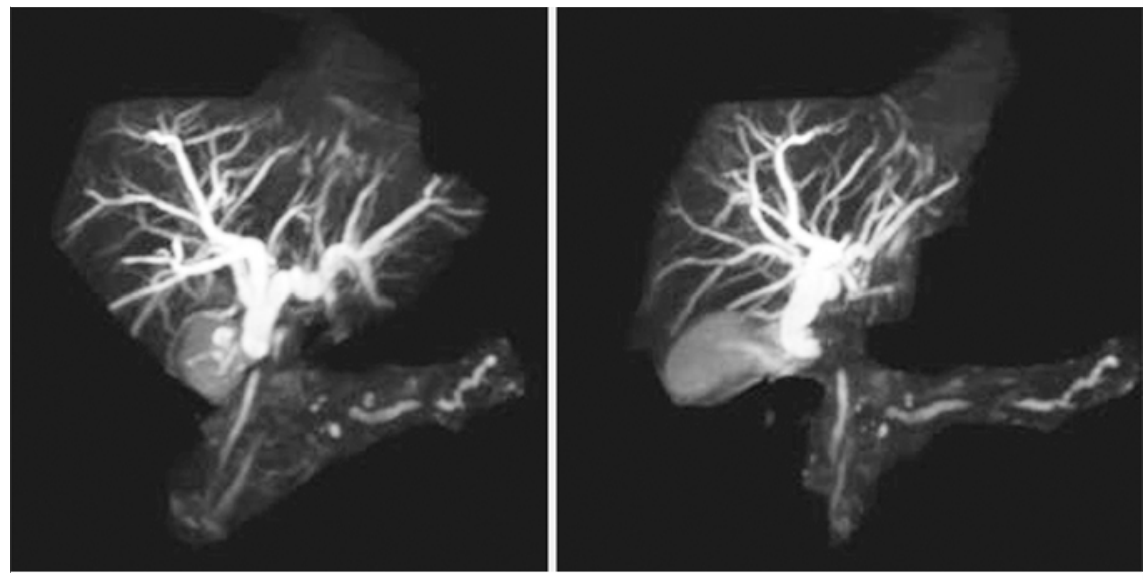

- Fig.2 Magnetic resonance cholangiopancreatography showed a perihilar biliary stricture with dilation of the intrahepatic bile duct.
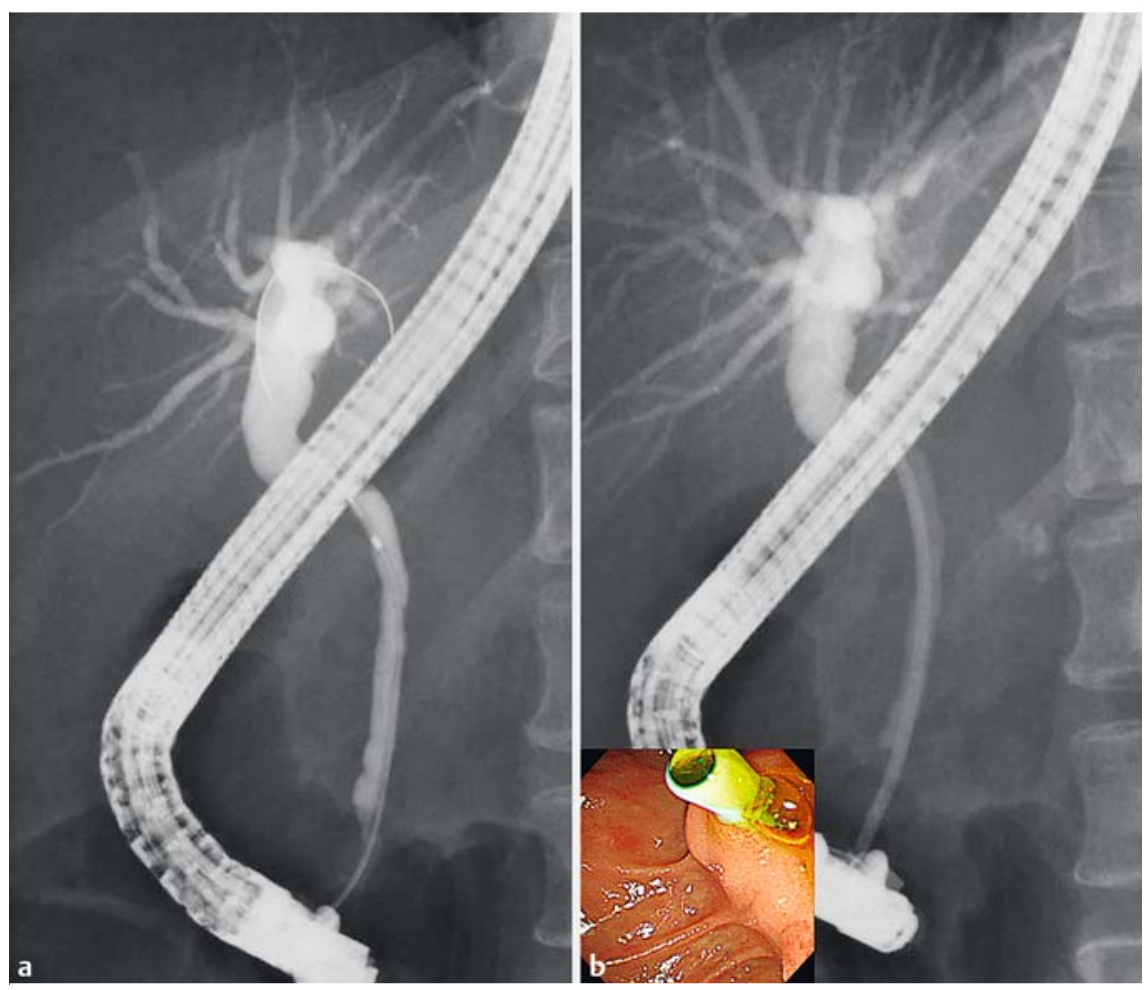

- Fig. 3 Radiographic images. a The perihilar biliary stricture. b A 7-Fr plastic stent was placed across the perihilar biliary stricture (inset: endoscopic view of the plastic stent through the ampulla of Vater). usefulness of a diathermic dilator for severe biliary strictures has been reported [1-5]. The use of diathermic dilation is also an effective rescue technique for unremovable occluded plastic stents.

Endoscopy_UCTN_Code_CPL_1AK_2AD

Competing interests

None

The Authors

Ryo Sugiura ${ }^{1,2}$, Hiroshi Kawakami ${ }^{2,3,4}$, Nobuyuki Ehira', Ichiro Iwanaga ${ }^{1}$, Minoru Uebayashi ${ }^{1}$, Masaki Kuwatani ${ }^{5}$, Naoya Sakamoto ${ }^{2}$

1 Department of Gastroenterology, Japanese Red Cross Kitami Hospital, Kitami, Japan

2 Department of Gastroenterology and Hepatology, Hokkaido University Hospital, Sapporo, Japan

3 Department of Gastroenterology and Hepatology, University of Miyazaki, Miyazaki, Japan

4 Center for Digestive Disease, University of Miyazaki Hospital, Miyazaki, Japan

5 Division of Endoscopy, Hokkaido University Hospital, Sapporo, Japan

\section{Corresponding author}

\section{Hiroshi Kawakami, MD, PhD}

Department of Gastroenterology and Hepatology, University of Miyazaki, Center for Digestive Disease, 5200, Kihara, Kiyotake-cho, 889-1692 Miyazaki, Japan Fax: +81-985-859802

hiropon@med.miyazaki-u.ac.jp 

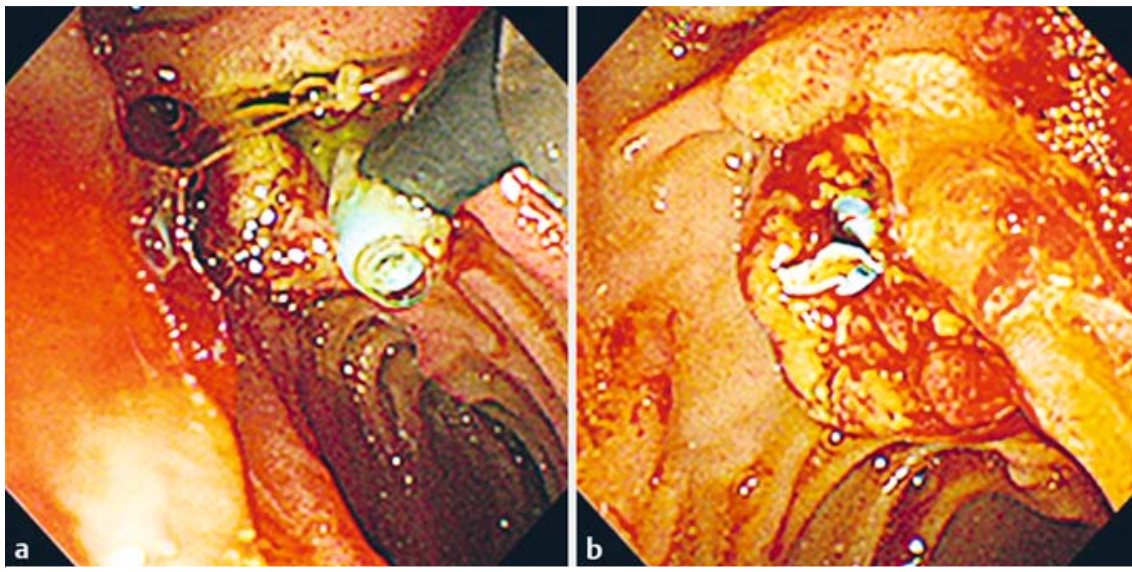

\section{Acknowledgment}

We express our deepest appreciation to Dr. Yunosuke Takishin, Kazuharu Suzuki, and Naoki Kawagishi (Department of Gastroenterology, Japanese Red Cross Kitami Hospital) for clinical advice.

- Fig. 4 Endoscopic images. a Snaring of the plastic stent after precut sphincterotomy with a needle-knife. $\mathbf{b}$ The torn-off plastic stent was left in place.
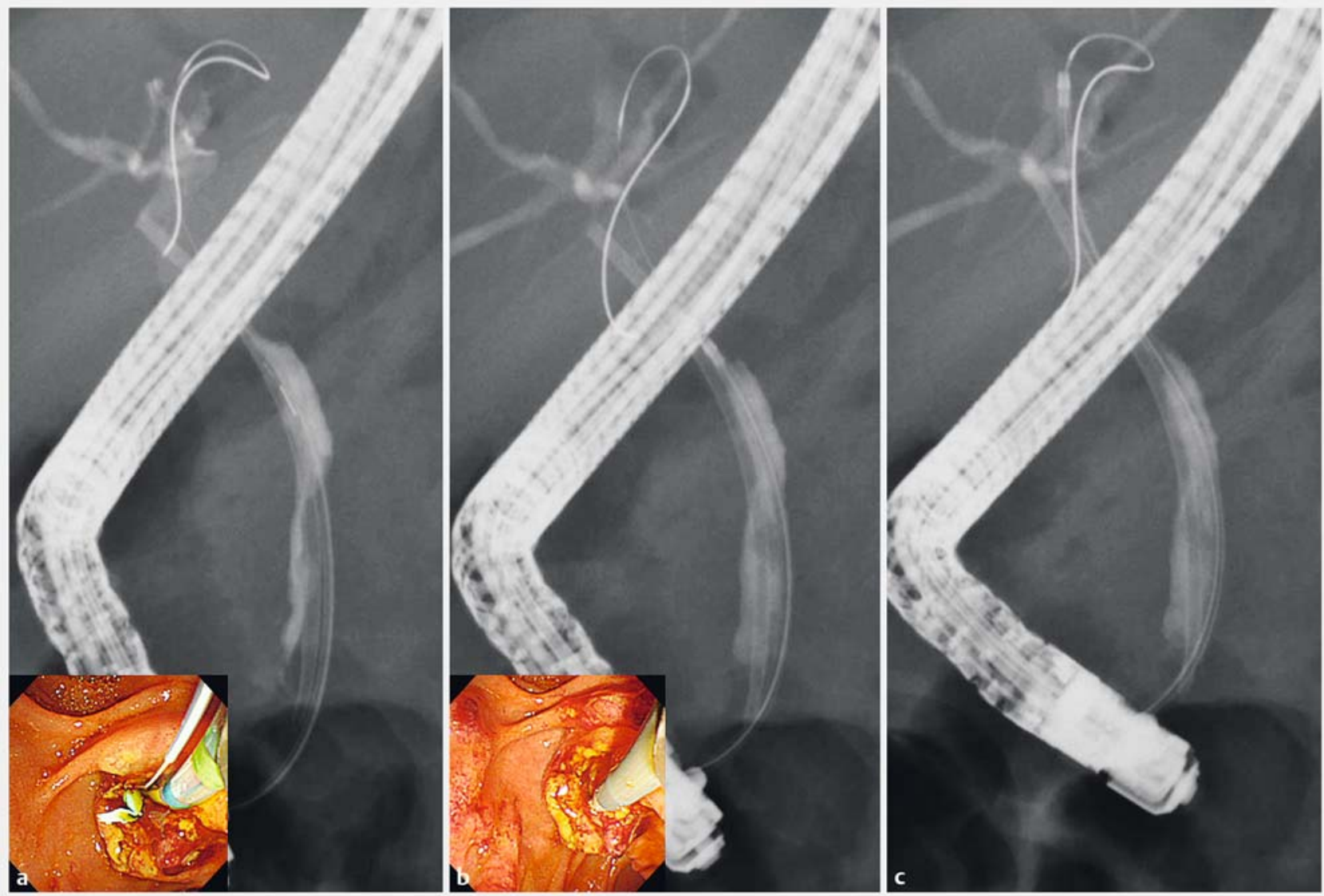

- Fig. 5 Radiographic images. a A 0.025-inch guidewire was advanced alongside the plastic stent (inset: endoscopic view). b, c A 6-Fr diathermic dilator was advanced alongside the perihilar biliary stricture (inset: endoscopic view). 


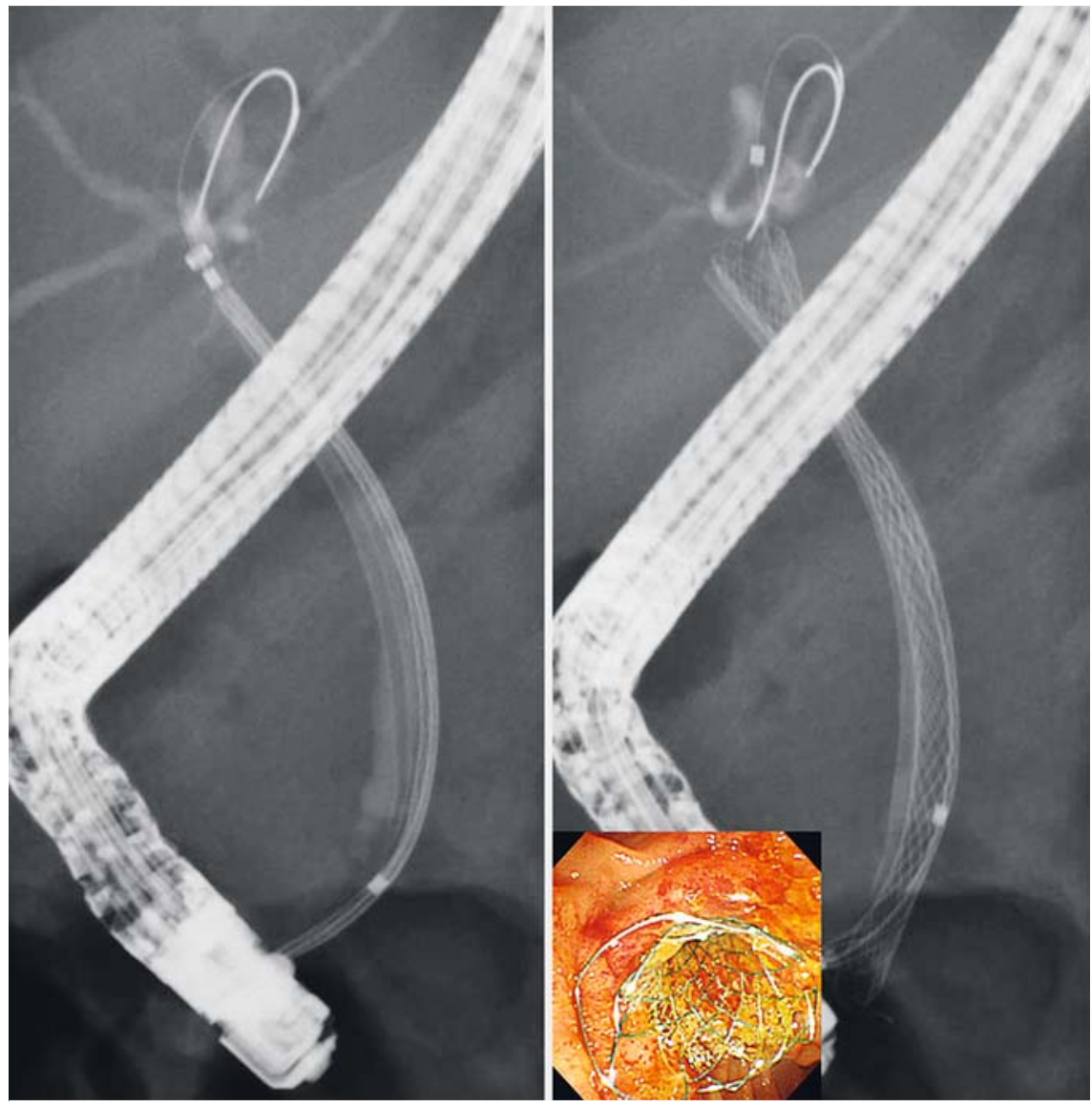

- Fig. 6 Radiographic images showing the partially covered, self-expandable, metallic stent placed over the stricture alongside the plastic stent.

\section{References}

[1] Kawakami H, Kuwatani M, Eto K et al. Resolution of a refractory severe biliary stricture using a diathermic sheath. Endoscopy 2012; 44 (Suppl. 02): E119- 120

[2] Kawakami H, Kuwatani M, Kawakubo K et al. Transpapillary dilation of refractory severe biliary stricture or main pancreatic duct by using a wire-guided diathermic dilator (with video). Gastrointest Endosc 2014; 79 : 338 343

[3] Kawakami H, Kuwatani M, Sakamoto N. Endoscopic ultrasound-guided antegrade diathermic dilation followed by self-expandable metallic stent placement for anastomotic stricture after hepaticojejunostomy (with video). Dig Endosc 2014; 26: $121-122$

[4] Kawakami H, Kuwatani M, Kawakubo K et al. Endoscopic ultrasound-guided antegrade diathermic dilation followed by self-expandable metal stent placement for malignant distal biliary stricture. Endoscopy 2014; 46 (Suppl. 01): E328-329

[5] Kawakami H, Abo D, Kawakubo K et al. Rendezvous biliary recanalization combining percutaneous and endoscopic techniques using a diathermic dilator for bile duct obstruction. Endoscopy 2014; 46 (Suppl. 01): E460-461

\section{Bibliography}

DOI http://dx.doi.org/10.1055/s-0042-121010

Endoscopy 2017; 49: E42-E45

(c) Georg Thieme Verlag KG

Stuttgart - New York

ISSN 0013-726X 